\title{
ESTUDO COMPARATIVO DO PERFIL DE ÁCIDOS GRAXOS EM SEMENTE DE PASSIFLORAS NATIVAS DO CERRADO BRASILEIRO ${ }^{1}$
}

\author{
RENATA MIRANDA LOPES ${ }^{2}$, ANDERSON CÁSSIO SEVILHA ${ }^{3}$, FÁBIO GELAPE FALEIRO $^{4}$, \\ DIJALMA BARBOSA DA SILVA ${ }^{3}$, ROBERTO FONTES VIEIRA ${ }^{3}$, \\ TÂNIA DA SILVEIRA AGOSTINI-COSTA ${ }^{3}$
}

RESUMO-No mundo, existem mais de 580 espécies de maracujazeiros, grande parte nativa da América Tropical e Subtropical, principalmente no Brasil. Os programas de melhoramento utilizam uma parte pequena dos recursos genéticos disponíveis, já que o potencial deste material geralmente não está suficientemente caracterizado. O objetivo deste trabalho foi a caracterização do teor de lipídios e do perfil de ácidos graxos presentes nas sementes de 03 espécies nativas silvestres de maracujás (Passiflora cincinnata, P. setacea e P. nitida), empregando o maracujá comercial ( $P$. edulis) como referência. Os lipídios totais foram extraídos com éter de petróleo em extrator tipo Soxhlet. O perfil dos ésteres metílicos foi caracterizado por cromatografia a gás, usando detector de ionização de chama. A espécie $P$. setacea apresentou o maior teor de óleo $(31,2-$ $33,5 \%)$, seguida por $P$. nitida $(29,5-32,3 \%)$ e $P$. cincinnata $(16,7-19,2 \%)$. O óleo de $P$. setacea apresentou $64,7 \%$ de ácido linoleico, $19,7 \%$ de oleico e $10,2 \%$ de ácido palmítico; o óleo de $P$. nitida apresentou os ácidos mirístico $(0,6 \%)$, palmítico $(15,3 \%)$, palmitoleico $(2,0 \%)$, oleico $(24,8 \%)$, linoleico $(51,7 \%)$ e um ácido graxo incomum às outras espécies de Passiflora, o láurico ( $0.4 \%)$; já o óleo de $P$. cincinnata apresentou os ácidos oleico $(11,0 \%)$, palmítico $(10,2 \%)$ e linoleico $(74,3 \%)$. O ácido linoleico foi predominante nas três espécies estudadas. Todas as espécies apresentaram ácido vacênico $(0,3-0,6 \%)$, descrito pela primeira vez no gênero Passiflora.

Termos para indexação: semente de maracujá, Cerrado, óleo, cromatografia a gás, ácido graxo.

\section{A COMPARATIVE STUDY OF FATTY ACIDS PROFILE OF PASSIFLORA SEED FROM BRAZILIAN SAVANA}

\begin{abstract}
There is more 580 species of passion fruit in the world; the majority is native from Tropical and Subtropical America, especially from Brazil. Breeding programs use a small part of genetic resources available, because the potential of this material is not sufficiently characterized. The objective of this work was the characterization of lipids content and fatty acids profile present in the seeds of 03 species of wild native passion fruit (Passiflora cincinnata, P. setacea e P. nitida) using commercial passion fruit (P. edulis) as reference. Total lipids were extracted with petroleum ether in Soxhlet extractor. The profile of methyl esters was characterized by gas chromatograph using flame ionization detector. The seeds of $P$. setacea showed higher content of oil (31.2-33.5 \%), followed by P. nitida (29.5-32.3\%) and P. cincinnata (16.7-19.2\%). The P. setacea oil presented $64.7 \%$ of linoleic, $10.2 \%$ of palmitic and $19.7 \%$ of oleic acid. P. nitida presented myristic $(0.6 \%)$, palmitic $(15.3 \%)$, palmitoleic $(2.0 \%)$, oleic $(24.8 \%)$, linoleic $(51.7 \%)$ and a not common acid in other Passiflora specie, the lauric acid (0.4\%); P. cincinnata showed oleic (11.0\%), palmitic (10.2\%) and linoleic acid (74.3\%). Linoleic acid was predominant in all evaluated species. All species presented vaccenic acid (0.3-0.6\%), described for first time in Passiflora genus.
\end{abstract}

Index terms: passion seed, oil, gas chromatography, fatty acid, Savanna.

\footnotetext{
1(Trabalho 138-09). Recebido em: 01-06-2009. Aceito para publicação em: 27-01-2010. Parte da monografia apresentada pelo primeiro autor para obtenção de título de Licenciatura em Ciências Biológicas, Faculdades da Terra de Brasília (FTB).

${ }^{2}$ Bióloga/ bolsista do Programa Biodiversidade Brasil-Itália - Embrapa Recursos Genéticos e Biotecnologia, Brasília-DF. E-mail: rm.lopes@yahoo.com.br.

${ }^{3}$ Pesquisadores/ Embrapa Recursos Genéticos e Biotecnologia, Parque Estação Biológica, PqEB, W5 Norte, final, CEP: 70770-900, Brasília-DF.E-mail: tania@cenargen.embrapa.br; dijalma@cenargen.embrapa.br; rfvieira@cenargen.embrapa.br; sevilha@cenargen. embrapa.br.

${ }^{4}$ Pesquisador/ Embrapa Cerrados, BR 020, Km 18, Caixa Postal 08223, 73010-970 Planaltina-DF. Email: ffaleiro@cpac.embrapa.br.
} 


\section{INTRODUÇÃO}

O gênero Passiflora apresenta cerca de 400 espécies, sendo que no Brasil são encontradas entre 111 e 150 espécies, principalmente no centro de distribuição geográfica deste gênero, que se localiza no Centro-Norte do Brasil. Mais de 40 espécies do gênero Passiflora foram identificadas em estado silvestre no Cerrado e nas áreas de transição. Não é por acaso que as maiores e mais diversificadas coleções de germoplasma do mundo estão no Brasil (FERREIRA et al., 2005). Além da diversidade genética relacionada às várias espécies do gênero Passiflora, resultados de pesquisas mostram grande diversidade genética intra-específica (BELLON et al., 2007; 2009; JUNQUEIRA et al., 2007) e a possibilidade de obtenção de vários híbridos interespecíficos (JUNQUEIRA et al., 2008; FONSECA et al., 2009). Apesar de toda esta variabilidade, somente duas espécies têm expressão comercial no Brasil, a Passiflora edulis Sims. edulis, (maracujá-azedo) e Passiflora alata Curtis (maracujá-doce). O maracujá-azedo é o mais conhecido, cultivado e comercializado devido à qualidade de seus frutos e ao seu maior rendimento industrial (FALEIRO et al., 2005).

As sementes provenientes do processo de obtenção da polpa de maracujá-azedo são utilizadas por produtores rurais na suplementação da alimentação animal, como ração para bovinos e aves, ainda que sem muita informação técnica adequada. Considerando o grande volume de semente produzida após o processamento da polpa, agregar valor a estes subprodutos é de interesse econômico, ambiental, científico e tecnológico (FERRARI et al., 2004).

Quimicamente, o óleo extraído da semente de P. edulis da Uganda (NYANZI et al., 2005) e óleos extraídos a partir de resíduos (sementes) do processamento de suco de maracujá-azedo de uma cooperativa de Santa Catarina (SANT'ANNA et al., 2001) e de uma indústria de Minas Gerais (FERRARI et al., 2004) apresentaram predominância dos ácidos linoleico $(67,8-70,1 \%)$, oleico $(15,0-18,1 \%)$, palmítico $(10,6-12,0 \%)$ e esteárico $(2,8-3,1 \%)$, seguidos por menores teores dos ácidos linolênico $(0,4-0,7 \%)$, palmitoleico $(0,4 \%)$, araquídico (traços- $0,2 \%)$, gadoleico (traços- $0,1 \%$ ), beênico (traços- $0,1 \%$ ), lignocérico (traços- $0,1 \%$ ) e mirístico (traços- $0,1 \%$ ) (SANT'ANNA et al., 2001; FERRARI et al., 2004; NYANZI et al., 2005).

Dentre as espécies nativas silvestres no Brasil, a P. cincinnata, a $P$. setacea e a $P$. nitida estão entre as mais conhecidas e entre as que apresentam potencial para uso econômico (OLIVEIRA; RUG-
GIERO, 2005). Estas espécies estão sendo utilizadas para consumo in natura ou na forma de sucos, doces, geleias e medicamentos ou como ornamental (FALEIRO et al., 2005). Por serem rústicas, tolerantes a pragas e doenças, e por apresentarem boa produtividade, com floração em períodos de entressafra do maracujá comercial, muitas das espécies nativas poderão, num futuro próximo, adquirir grande importância social e ambiental por gerar emprego e renda em áreas marginais para a agricultura convencional e dispensar o uso de defensivos agrícolas (JUNQUEIRA et al., 2005).

O objetivo deste artigo foi determinar o teor de lipídios, a proporção de suco e semente e a composição dos ésteres metílicos de ácidos graxos presentes nas sementes de 11 acessos obtidos a partir de três espécies silvestres de Passiflora (P. cincinnata Mast., P. setacea DC. e P. nitida Kunth), empregando a espécie comercial (P. edulis Sims var. flavicarpa) como referência.

\section{MATERIAL E MÉTODOS}

\section{Material vegetal e preparo da amostra}

Foram coletados quatro acessos (12 a 30 frutos /acesso) de $P$. cincinnata e um acesso de $P$. setacea em localidades diferentes do norte do Estado de Minas Gerais, em outubro de 2006; três acessos de $P$. nitida e três acessos de $P$. setacea no Banco de germoplasma de Passiflora da Embrapa Cerrados, Planaltina-DF, entre outubro de 2007 e fevereiro de 2008; os frutos de P. edulis Sims var. flavicarpa empregados como referência foram adquiridos em hipermercados de Brasília, entre outubro de 2007 e março de 2008.

Os frutos coletados no norte de Minas Gerais foram acondicionados em isopor com gelo e transportados diretamente ao Laboratório de Química de Produtos Naturais da Embrapa Recursos Genéticos e Biotecnologia, onde foram realizados uma triagem, a limpeza e o acondicionamento em freezer a $-20^{\circ} \mathrm{C}$, até o momento da análise. Os frutos coletados no Banco de Germoplasma da Embrapa Cerrados e os frutos adquiridos em hipermercado foram imediatamente preparados para as análises químicas.

Os frutos foram cortados em duas partes, e a polpa foi transferida para uma peneira; o suco foi extraído e as sementes foram coletadas separadamente e transferidas para um liquidificador doméstico (as hastes foram protegidas com fita adesiva para evitar o corte das sementes), onde foram friccionadas com água para a remoção da mucilagem. Casca, polpa e semente de alguns acessos/espécies de Passiflora 
foram pesadas separadamente, para avaliação da proporção de cada componente.

As sementes foram submetidas a um processo de pré-secagem à temperatura ambiente (25 ${ }^{\circ} \mathrm{C}$, umidade relativa $30-60 \%$ ) por $48 \mathrm{~h}$. Para a determinação do perfil de ésteres metílicos de ácidos graxos, as sementes foram posteriormente secas em estufa com circulação e renovação de ar forçado a 48 ${ }^{\circ} \mathrm{C}$ por $24 \mathrm{~h}$. Em seguida, as sementes foram trituradas em grau e pistilo para a obtenção de um farelo fino e homogêneo (granulometria de 18 mesh).

\section{Teor de lipídios e umidade}

O teor de umidade das sementes de algumas espécies/acessos de Passiflora foi determinado em triplicata por secagem do farelo em estufa ventilada $\left(105^{\circ} \mathrm{C}\right)$ até peso constante. $\mathrm{O}$ teor de lipídios das sementes de algumas espécies/acessos de Passiflora foi determinado no farelo seco por extração contínua a quente $\left(70{ }^{\circ} \mathrm{C}\right)$ com éter de petróleo $40-60{ }^{\circ} \mathrm{C}$ em extrator de gordura (Tecnal). Após a recuperação automática do solvente no próprio extrator de gordura, o resíduo foi levado para uma estufa onde permaneceu por 30 min a $100{ }^{\circ} \mathrm{C}$, para evaporação total do solvente residual. $\mathrm{O}$ teor de óleo foi determinado por pesagem do resíduo totalmente seco (POMERANZ; MELOAN, 1994; CECCHI, 1999).

\section{metílicos}

Extração do óleo e obtenção dos ésteres

O óleo da semente de Passiflora foi extraído com éter de petróleo $40-60{ }^{\circ} \mathrm{C}$ em extrator de gordura (Tecnal), filtrado, e o solvente totalmente evaporado a vácuo (temperatura máxima de $60^{\circ} \mathrm{C}$ ). O óleo obtido foi acondicionado em vial de $4 \mathrm{~mL}$ e conservado em freezer a $-20^{\circ} \mathrm{C}$ até o momento da transesterificação.

A transesterificação com metanol (em triplicata) foi feita por catálise alcalina com $\mathrm{KOH}$, conforme descrito por Murrieta et al. (2003), visando a manter a eficiência da reação e a preservar a estabilidade dos ésteres do ácido linoleico, que é o principal ácido graxo de Passiflora.

\section{metílicos}

Identificação e quantificação dos ésteres

A composição dos ésteres metílicos de ácidos graxos foi determinada por cromatografia em fase gasosa, sendo empregado um cromatógrafo Shimadzu Class GC 10 equipado com detector de ionização de chama (FID) e sistema de injeção automática AOC20. Os compostos foram separados em coluna capilar DB-23 Agilent (50\% cianopropil - metilpolisiloxano; diâmetro interno: 0,25 mm; espessura do filme: 0,25 $\mu \mathrm{m}$; comprimento: $60 \mathrm{~m}$ ) de acordo com metodologia estabelecida pela American Oil Chemists' Society
- AOCS (AOCS, 1988). Condições de operação do cromatógrafo: fluxo coluna: $1,00 \mathrm{~mL} / \mathrm{min}$; velocidade linear do gás de arraste: $24 \mathrm{~cm} / \mathrm{seg}$; temperatura do detector: $280^{\circ} \mathrm{C}$; temperatura do injetor: $250{ }^{\circ} \mathrm{C}$; temperatura forno: $110^{\circ} \mathrm{C}-5$ minutos, $110-215^{\circ} \mathrm{C}$ $\left(5{ }^{\circ} \mathrm{C} / \mathrm{min}\right), 215^{\circ} \mathrm{C}-24$ minutos; gás de arraste: hélio; volume injetado: $1,0 \mu \mathrm{L}$.

Os ésteres metílicos dos ácidos graxos foram analisados por coinjeção de padrões. Para determinar o tempo de retenção dos ésteres metílicos de ácidos graxos (FAME), foram injetados padrões Supelco contendo 10 ésteres metílicos de ácidos graxos e 14 ésteres metílicos de ácidos graxos insaturados, incluindo, em ordem crescente de tempo de retenção, os seguintes FAME: C6:0, C8:0, C10:0, C12:0, C14:0, C14:1, C16:0, C16:1, C18:0, C18:1 Z-9, C18:1 Z-11, C18:2, C18:3, C20:0, C20:1; C20:4; C22:0; C22:1; C24:0, C24:1.

Para confirmar a identidade dos ésteres metílicos do ácido vacênico (C18:1 Z-11) e do ácido láurico (C12:0), descritos pela primeira vez em óleos destas espécies de Passiflora, os padrões destes ésteres metílicos foram adicionados às respectivas amostras transesterificadas (spiking), o que resultou em aumento proporcional dos picos correspondentes.

\section{Análise estatística}

Os valores médios observados para as determinações do teor de óleo, da umidade e da composição de FAME (todas as determinações foram feitas em três repetições) para uma mesma espécie e para diferentes espécies de Passiflora foram comparados por análise de variância (ANOVA) mediante o teste de Scheffé $(p>0,05)$ através do SAS System versão 9.0 para Windows - 2002 (SAS, 1992), conforme modelo utilizado por Oh et al. (2007) para o mesmo tipo de experimento.

\section{RESULTADOS E DISCUSSÃO}

\section{Teor de umidade e lipídios}

Os teores de umidade e lipídios totais (em base seca) presentes nas sementes de diferentes espécies de Passiflora encontram-se na Figura 1. As sementes de $P$. edulis apresentaram 27,3-28,0 g $100 \mathrm{~g}^{-1}$ de lipídios. Os teores de lipídios de todos

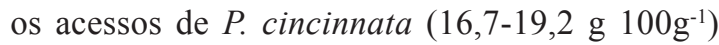
diferiram significativamente $(\mathrm{p}>0,05)$ de $P$. edulis e diferiram, também, das outras espécies nativas silvestres. Não foi observada, entretanto, nenhuma variação significativa entre os teores de óleo de $P$.

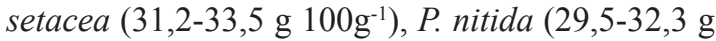

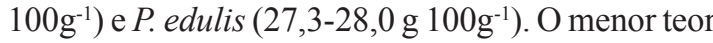
de lipídios presente na semente do $P$. cincinnata pode 
estar associado à presença de um tegumento lignificado grosso na semente desta espécie, ao contrário de $P$. setacea, que apresenta um tegumento bastante fino. Os teores de lipídios encontrados em sementes de Passiflora da Uganda (P. edulis Sims var. edulis; P. edulis Sims var. flavicarpa; P. maliformis L.)

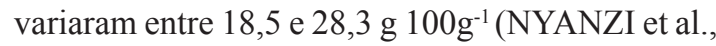
2005). A variação encontrada neste estudo foi um

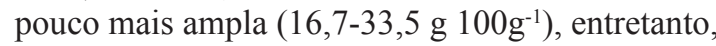
dentro do esperado, já que foram avaliadas quatro espécies de Passiflora, sendo três distintas das espécies consideradas por Nyanzi et al. (2005).

\section{Proporção de suco, casca e semente}

Os frutos avaliados neste estudo apresentaram proporção de casca, suco e sementes de acordo com a Figura 2, sendo que $P$. edulis, empregado como referência, mostrou resultados semelhantes aos encontrados por Ferrari et al. (2004). Com relação à proporção de suco, $P$. nitida, que foi obtida no Banco de Germoplasma de Passiflora, mostrou menor proporção, diferindo significativamente $(\mathrm{p}>$ $0,05)$ de $P$. edulis, de $P$. setacea e de $P$. cincinnata procedentes do mesmo Banco, mas não diferiu significativamente destas espécies, quando procedentes da região de Montes Claros. Quanto à casca, P. niti$d a$, com maior proporção, diferiu significativamente de $P$. edulis (referência) e das 03 espécies nativas silvestres de ambas as origens. Com relação às sementes, $P$. nitida não diferiu de $P$. edulis, embora tenha apresentado menores percentuais que a $P$. setacea de Montes Claros e a $P$. cincinnata de ambas as origens. Além das diferenças observadas para o $P$. nitida, apenas o $P$. cincinnata de Montes Claros diferiu significativamente da espécie empregada como referência ( $P$. edulis), para a proporção de semente com percentual mais elevado. As demais espécies não apresentaram diferença significativa de $P$. edulis quanto à proporção de suco, semente ou casca.

\section{(FAME)}

Perfil de ésteres metílicos de ácidos graxos

O óleo de P. edulis, empregado como referência, mostrou composição semelhante à citada por outros autores (SANT'ANNA et al., 2001; FERRARI et al., 2004; NYANZI et al., 2005), sendo que a coluna utilizada neste estudo permitiu ainda a separação adicional do ácido vacênico (C18:1 Z-11), que foi comparado com padrão por cocromatografia, conforme dados da literatura para este tipo de análise (CHAVES et al., 2004; OH et al., 2007). Os perfis de ésteres metílicos de ácidos graxos obtidos das sementes de maracujá estão apresentados na Tabela 1. Predominaram os ácidos linoleico (C18:2), oleico
(C18:1 Z-9), palmítico (C16:0) e esteárico (C18:0), seguidos por menores teores dos ácidos linolênico (C18:3), palmitoleico (C16:1), vacênico (C18:1 Z-11), mirístico (C14:0), araquídico (C20:0) e gadoleico (C20:1).

Assim como em P. edulis, os óleos das espécies nativas silvestres de Passiflora também apresentaram predominância de ácidos graxos polinsaturados, especialmente ácido linoleico (Tabela 1), mas em proporções significativamente diferentes $(p>0,05)$. Para os ácidos graxos palmítico, oleico, linoleico e para insaturados, todas as espécies nativas silvestres, com exceção de $P$. setacea, diferiram significativamente da espécie comercial $P$. edulis. O óleo de $P$. cincinnata apresentou o maior teor de ácido linoleico (74,3\%), e o óleo de P. nitida apresentou o menor teor deste ácido graxo (51,7\%). Os teores de ácido oleico foram superiores a $24 \%$ na espécie $P$. nítida, e $P$. cincinata apresentou o menor valor deste ácido graxo monoinsaturado (11\%), diferindo significativamente de $P$. edulis. O óleo de $P$. cincinnata apresentou o maior teor de insaturados (86,3\%); óleo de $P$. nitida apresentou o menor teor insaturados (79,8\%). Já o ácido esteárico, encontrado em menores concentrações (2,9-3,5\%), manteve-se estável em todas as espécies de Passiflora avaliadas neste estudo. Adicionalmente, P. nitida apresentou pequenos teores $(0,3 \%)$ de um ácido graxo incomum ao gênero Passiflora, o ácido láurico (C12: 0) (Figura 3).

Considerando apenas espécies de Passiflora nativas silvestres, a composição de ácidos graxos nas sementes foi reportada em apenas um acesso de $P$. nitida procedente do Banco de Germoplasma do IAC (VIEIRA, 2006). Embora os teores de ácido linoleico tenham sido menores $(35,5 \%)$ e os teores de ácido oleico maiores $(28,4 \%)$ do que o encontrado em nosso estudo, esta dissertação (VIEIRA, 2006) confirma a menor abundância de ácidos graxos instaurados $(64,4 \%)$ no $P$. nitida em relação ao $P$. edulis $(82,6 \%)$.

Pequenas variações significativas $(2,2$ a $10,3 \%$ ) foram observadas na composição de ácidos graxos dentro de uma mesma espécie de Passiflora nativa silvestre, com destaque para $P$. cincinnata (acesso II de Montes Claros e acesso I do CPAC) e P. setacea (amostra III do CPAC). Coeficiente de variação maior $(23,6 \%)$ foi observado apenas para os teores de ácido linoleico da espécie $P$. cincinnata. Além da influência genética, a temperatura tem sido identificada como o mais importante fator que influencia na biogênese (biossíntese) de ácidos graxos polinsaturados (NYANZI et al., 2005). 


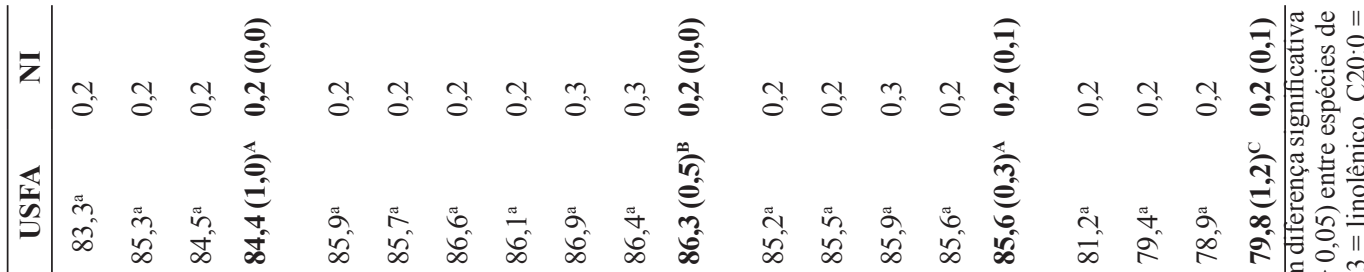

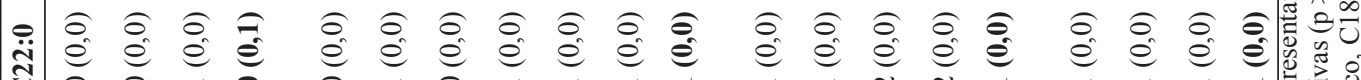

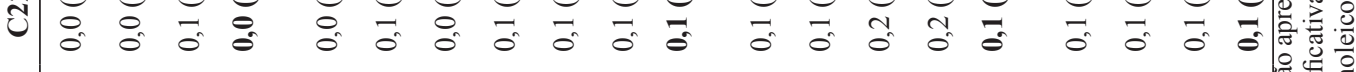

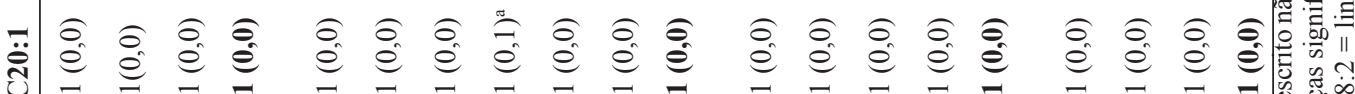

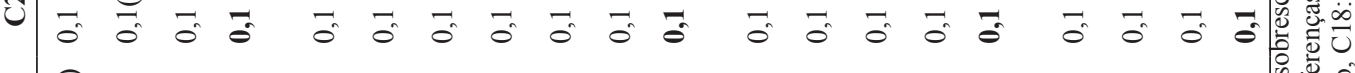

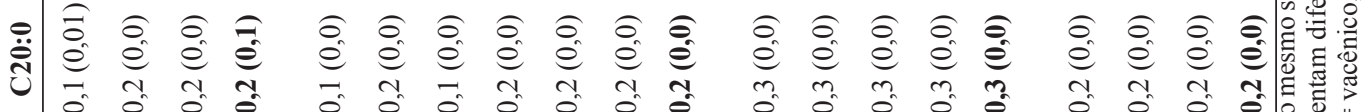

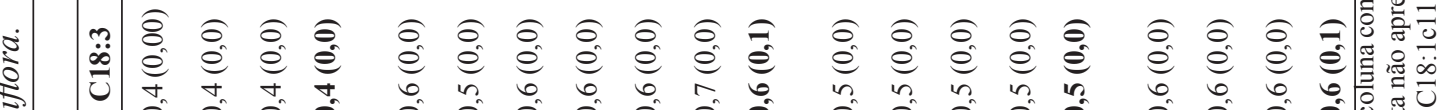

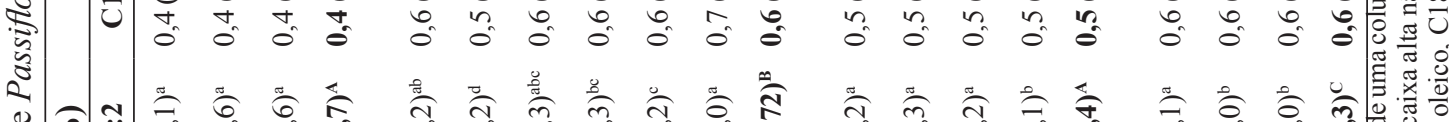

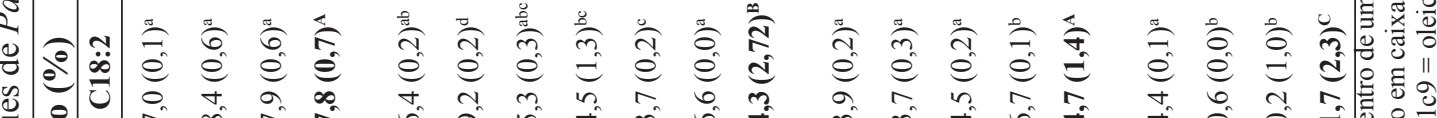

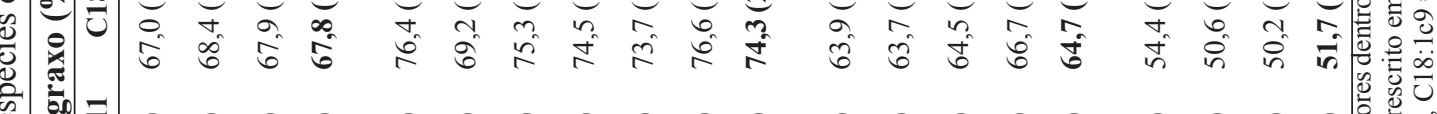

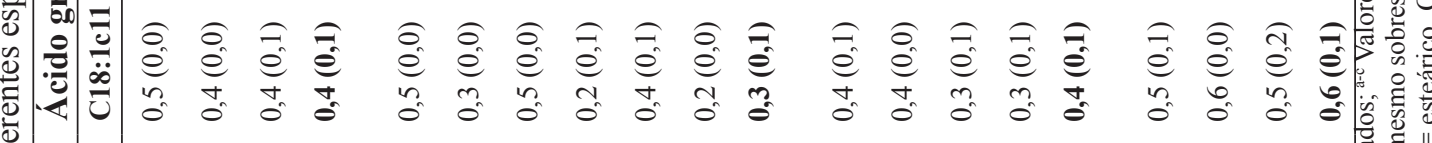

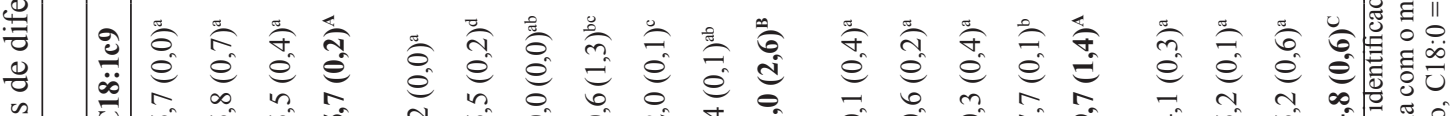

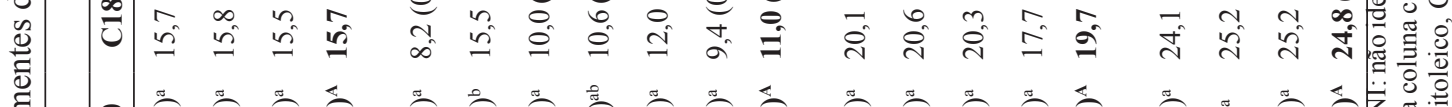

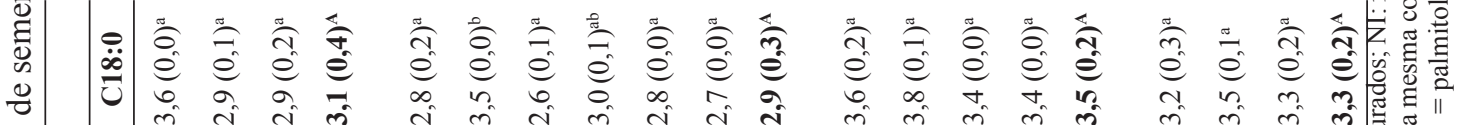

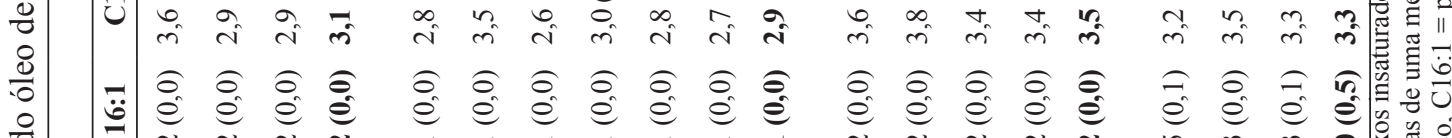

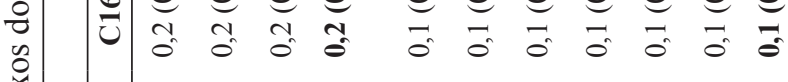

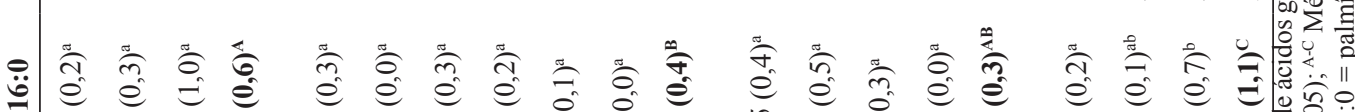

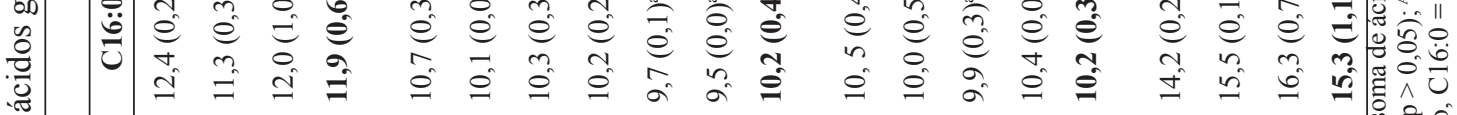

o

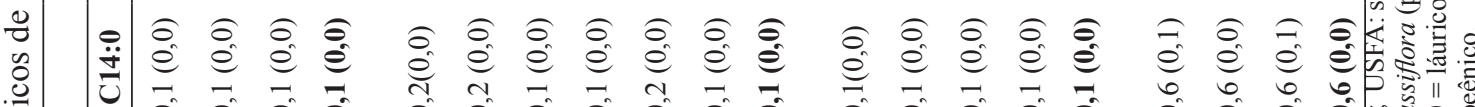

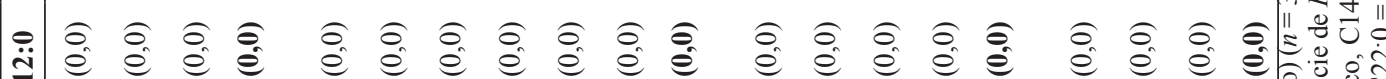

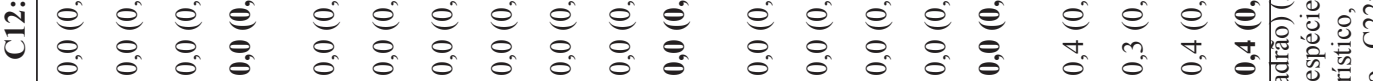

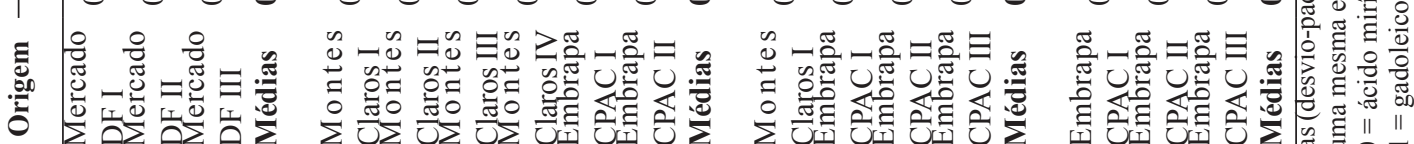

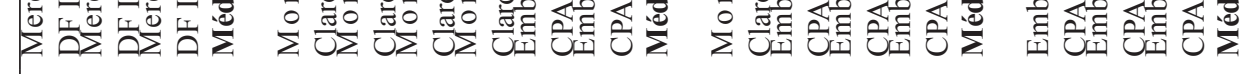

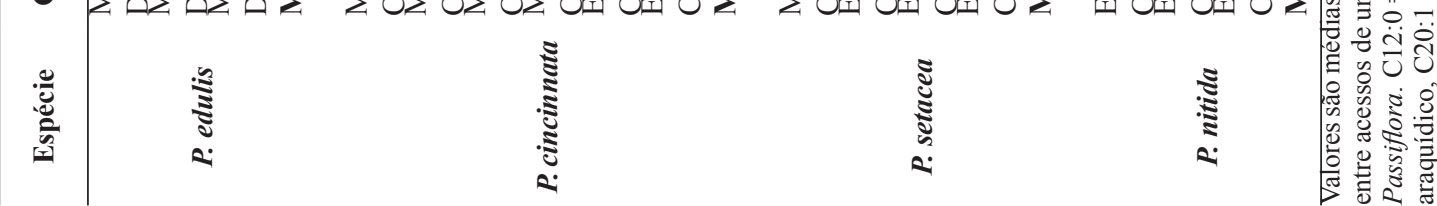




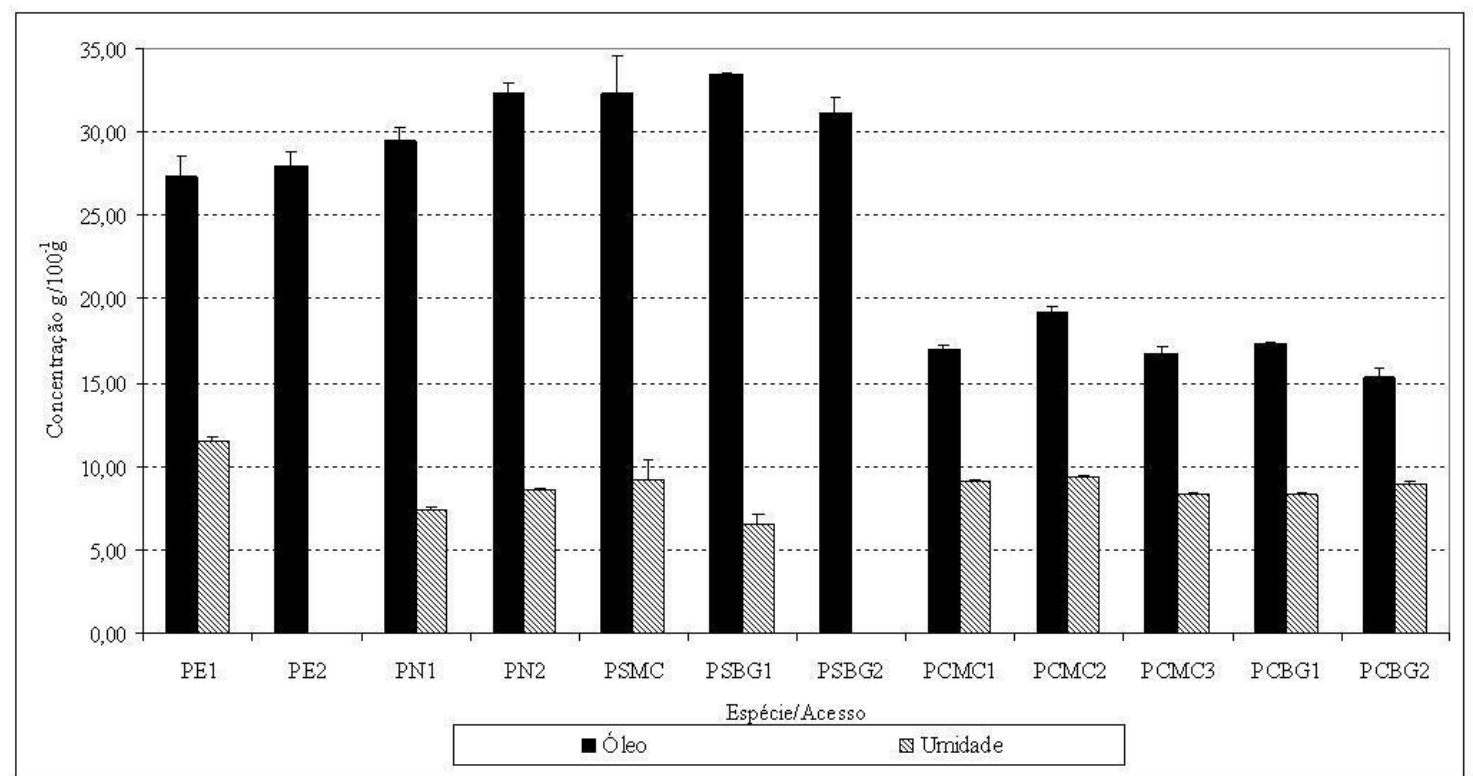

FIGURA 1 - Teores de umidade e lipídios, em base seca, nas sementes de Passiflora; valores são médias (desvio-padrão) (n = 3); PE: P. edulis; PN: P. nitida; PSMC: P. setacea de Montes Claros; PSBG: P. setacea do Banco de Germoplasma de Passiflora, Planaltina-DF; PCMC: P. cincinnata da região de Montes Claros; PCBG: P. cincinnata do Banco de Germoplasma de Passiflora, Planaltina-DF.

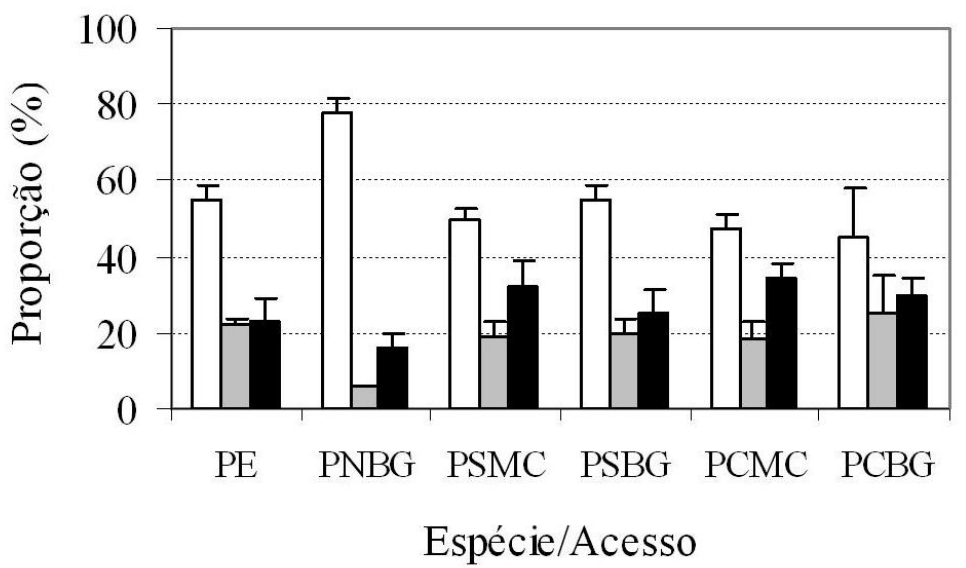

\section{$\square$ Casca $\square$ Suco $\square$ Semente}

FIGURA 2 - Proporção de suco, semente e casca em frutos de diferentes espécies de Passiflora; valores são médias (desvio-padrão) (n=3); PE: P. edulis; PNBG: P. nitida do Banco de Germoplasma de Passiflora, Planaltina-DF; PSMC: P. setacea da região de Montes Claros; PSBG: P. setacea do Banco de Germoplasma de Passiflora, Planaltina-DF; PCMC: P. cincinnata da região de Montes Claros; PCBG: P. cincinnata do Banco de Germoplasma de Passiflora, Planaltina-DF. 


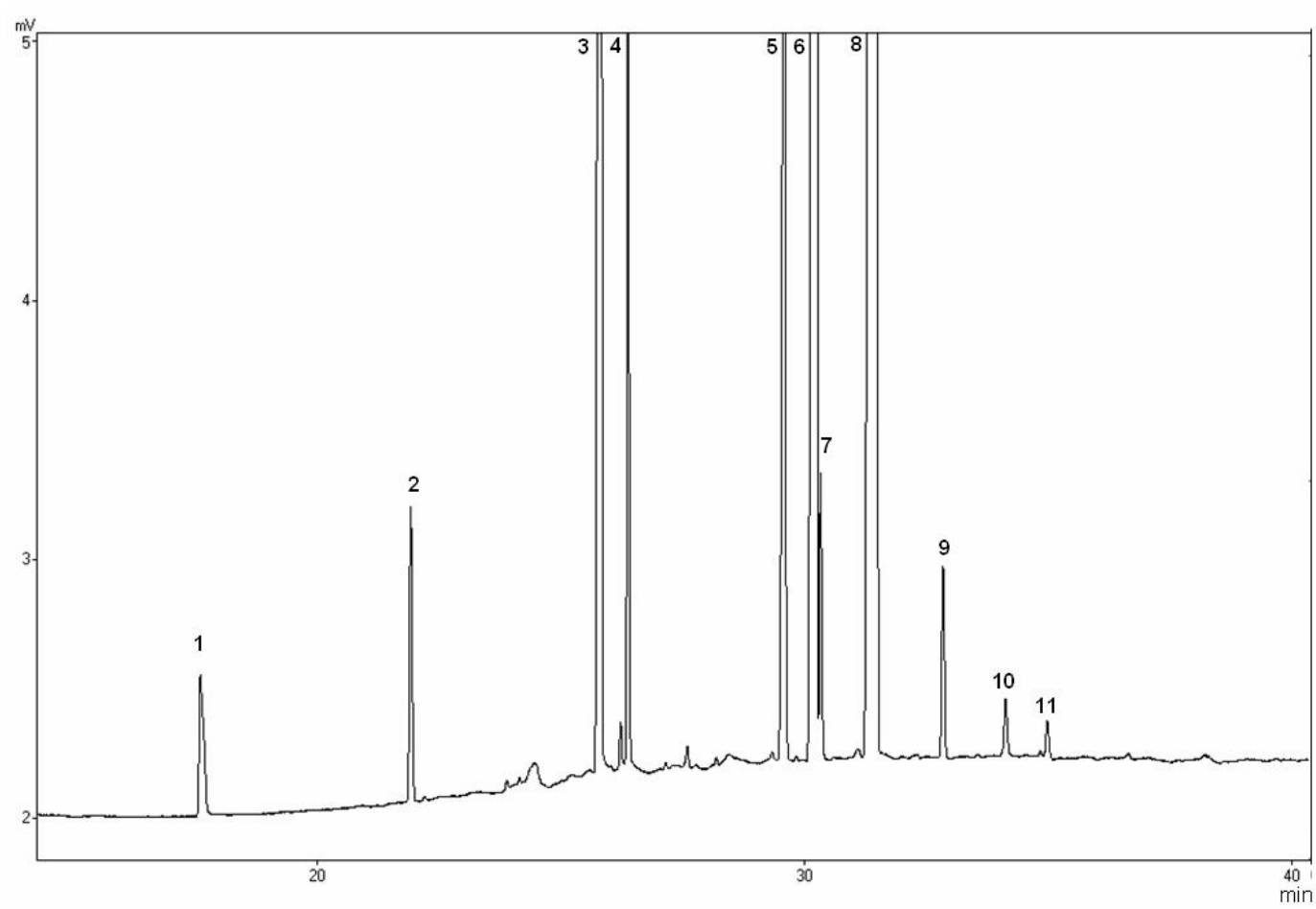

FIGURA 3 - Perfil dos ésteres metílicos dos ácidos graxos do óleo da semente de Passiflora nitida. Análise por GC-FID e identificação por coinjeção de padrões. 1- Ácido láurico (C12:0); 2- Ácido mirístico (C14:0); 3- Ácido palmítico (C16:0); 4- Ácido palmitoleico (C16:1); 5- Ácido esteárico (C18:0); 6- Ácido oleico (C18:1 Z-9); 7- Ácido vacênico (C18:1 Z-11); 8- Ácido linoleico (C18:2); 9- Ácido linolênico (C18:3) 10- Ácido araquídico (C20:0); 11- Ácido gadoleico (C20:1).

\section{CONCLUSÕES}

O estudo comparativo de óleos de sementes de diferentes espécies de Passiflora demonstra que a espécie $P$. cincinnata apresenta a maior proporção de semente (30 a 34\%); entretanto, como possui um tegumento espesso, apresenta menor teor de óleo

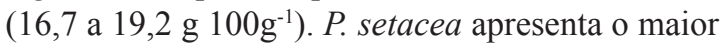

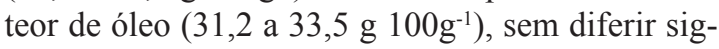

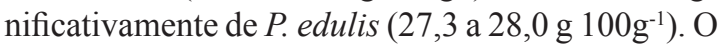
óleo de $P$. cincinnata mostra predominância do ácido graxo essencial linoleico (C18:2), também conhecido como ômega-6 (74,3\%) e o óleo de $P$. nitida apresenta o maior teor do ácido graxo monoinsaturado oleico (C18:1) (24,8\%), considerados interessantes do ponto de vista nutricional e tecnológico, respectivamente. O elevado teor de ácido linoleico (C18:2), em todas as espécies avaliadas neste estudo, é semelhante ao que ocorre no óleo de semente de girassol (TELLES, 2006). Óleos, como os de semente de Passiflora, que apresentam elevado teor de ácidos graxos polinsaturados, podem ser empregados com sucesso, por exemplo, na produção de margarinas, que são con- sumidas sem tratamento térmico e, por isso, menos suscetíveis à oxidação. Além disso, a composição do óleo de semente de Passifloras também poderá ser avaliada como base para a produção de cosméticos.

\section{AGRADECIMENTOS}

Ao Programa Biodiversidade Brasil-Itália PBBI, pelo financiamento da pesquisa, e ao Centro de Agricultura Alternativa-CAA, de Montes Claros, Minas Gerais, pela colaboração.

\section{REFERÊNCIAS}

AOCS - AMERICAN OIL CHEMISTS SOCIETY. Official and Tentative Methods of the American Oil Chemists Society. $3^{\text {rd }}$ ed. Chicago: AOCS, 1988. 
BELLON, G.; FALEIRO, F.G.; JUNQUEIRA, K.P.; JUNQUEIRA, N.T.V.; SANTOS, E.C.; BRAGA, M.F.; GUIMARÃES, C.T. Variabilidade genética de acessos silvestres e comerciais de Passiflora edulis Sims. com base em marcadores RAPD. Revista Brasileira de Fruticultura, Jaboticabal, v.29, n.1, p. 124-127, 2007.

BELLON, G.; FALEIRO, F.G.; PEIXOTO, J.R.; JUNQUEIRA, K.P.; JUNQUEIRA, N.T.V.; FONSECA, K.G.; BRAGA, M.F. Variabilidade genética de acessos obtidos de populações cultivadas e silvestres de maracujazeiro-doce com base em marcadores RAPD. Revista Brasileira de Fruticultura, Jaboticabal, v. 31, n. 1, p. 197-202, 2009.

CECCHI, H. M. Fundamentos teóricos e práticos em análise de alimentos. 2.ed. Campinas: Unicamp, 1999. 207 p.

CHAVES, M. H.; BARBOSA, A. S.; MOITA NETO, J. M.; AUED-PIMENTEL, S.; LAGO, J. H. Caracterização química do óleo da amêndoa de Sterculia striata St. Hil. et Naud. Química Nova, São Paulo, v. 27, n. 3, p. 404-408, 2004.

FALEIRO, F.; JUNQUEIRA, N. T. V.; BRAGA, M. F.; PEIXOTO, J. R.; JUNQUEIRA, N. T.V. Germoplasma e melhoramento genético do maracujazeiro: desafios da pesquisa. In: FALEIRO, F.G.; JUNQUEIRA, N.T.V.; BRAGA, M.F. Maracujá: germoplasma e melhoramento genético. Planaltina: Embrapa Cerrados, 2005. p. 187- 202.

FERRARI, R. A.; COLUSSI, F.; AYUB, R. Caracterização de subprodutos da industrialização do maracujá - aproveitamento das sementes. Revista Brasileira de Fruticultura, Jaboticabal, v. 26, n. 1, p. 101-107, 2004.

FERREIRA, F.R. Recursos genéticos de Passiflora. In: FALEIRO, F.G.; JUNQUEIRA, N.T.V.; BRAGA, M.F. Maracujá: germoplasma e melhoramento genético. Planaltina: Embrapa Cerrados, 2005. p. 41-50.

FONSECA, K.G.; FALEIRO, F.G.; JUNQUEIRA, N.T.V.; PEIXOTO, J.R.; BELLON, G.; JUNQUEIRA, K.P.; SANTOS, E.C. Análise da recuperação do genoma recorrente em maracujazeiro-azedo com base em marcadores RAPD. Revista Brasileira de Fruticultura, Jaboticabal, v. 31, n. 1, p. 145-153, 2009.
JUNQUEIRA, N. T. V.; BRAGA, M. F; FALEIRO, F. G.; PEIXOTO, J.R.; BERNACCI, L. C. Potencial de espécies silvestres de maracujazeiro como fonte de resistência a doenças. In: FALEIRO, F.G.; JUNQUEIRA, N.T.V.; BRAGA, M.F. Maracujá: germoplasma e melhoramento genético. Planaltina: Embrapa Cerrados, 2005. p. 81-106.

JUNQUEIRA, K.P.; FALEIRO, F.G.; JUNQUEIRA, N.T.V.; BELLON, G.; RAMOS, J.D.; BRAGA, M.F.; SOUZA, L.S. Confirmação de híbridos interespecíficos artificiais no gênero Passiflora por meio de marcadores RAPD. Revista Brasileira de Fruticultura, Jaboticabal, v.30, n.1, p. 191-196, 2008.

JUNQUEIRA, K.P.; FALEIRO, F.G.; RAMOS, J.D.; BELLON, G.; JUNQUEIRA, N.T.V.; BRAGA, M.F. Variabilidade genética de maracujá-suspiro (Passiflora nitida Kunth.) com base em marcadores moleculares. Revista Brasileira de Fruticultura, Jaboticabal, v.29, n.3, p. 571-575, 2007.

MURRIETA, C.M.; HESS, B. W.; RULE, D. C. D. Comparison of acidic and alkaline catalysts for preparation of fatty acid methyl esters from ovine muscle with emphasis on conjugated linoleic acid. Meat Science, Oxford, v. 65, n. 1, p. 523-529, 2003.

NYANZI, S. A.; CARSTENSEN, B.; SCHWACK, W. A. A Comparative Study of Fatty Acid Profiles of Passiflora Seed Oils from Uganda. Journal of the American Oil Chemists' Society, Champaign, v. 82 , n. 1, p. 41-44, 2005.

OH, H. H.; HWANG, K. T.; SHIN, M. K.; LEE, H. K.; KIM, S. Z. Oils in the Seeds of Caneberries Produced in Korea. Journal of the American Oil Chemists' Society, Champaign, v. 84, n. 6, p. 549$555,2007$.

OLIVEIRA, J.C. de; RUGGIERO, C. Espécies de maracujá com potencial agronômico. In: FALEIRO, F.G.; JUNQUEIRA, N.T.V.; BRAGA, M.F. Maracujá: germoplasma e melhoramento genético. Planaltina: Embrapa Cerrados, 2005. p.143-158.

POMERANZ, Y.; MELOAN, C. E. Food analysis: theory and practice. 3. ed. New York: Chapman \& Hall, 1994. 778p. 
SANT'ANNA, E.; TORRES, R. C.; PORTO, A. C. S. Avaliação de diferentes métodos cromatográficos na determinação de ácidos graxos em sementes de maracujá (Passiflora edulis f. flavicarpa). Boletim CEPPA, Curitiba, v. 19, n. 1, p. 85-94, 2001.

\section{SAS - Statistical analysis system for Windows} versão 9.0. Cary, 2002.

TELLES, M. M. Caracterização dos grãos, torta e óleo de três variedades de girassol (Helianthus annuus L.) e estabilidade do óleo bruto. $2006.70 \mathrm{f}$. Dissertação (Mestrado em Ciência dos Alimentos) Departamento de Ciência e Tecnologia de Alimentos do Centro de Ciências Agrárias, Universidade Federal de Santa Catarina, Florianópolis, 2006.
VIEIRA, M. A. R. Caracterização dos ácidos graxos das sementes e compostos voláteis dos frutos de espécies do gênero Passiflora. 2006. 60 f. Dissertação (Mestrado em Agronomia - área de concentração em Horticultura) - Faculdade de Ciências Agronômicas, Universidade Estadual Paulista, Botucatu, 2006. 